\title{
Imaging of body composition in children
}

\author{
Paolo Simoni ${ }^{1}$, Riccardo Guglielmi ${ }^{2}$, Maria Pilar Aparisi Gómez ${ }^{3,4}$ \\ ${ }^{1}$ Pediatric Imaging, Diagnostic Imaging Department, Queen Fabiola Children's University Hospital, Université Libre de Bruxelles, Bruxelles, \\ Belgium; ${ }^{2}$ Department of Radiology, St Gallen University Hospital, Kantonal Hospital Müsterlingen, Münsterlingen, Switzerland; ${ }^{3}$ Department of \\ Radiology, Auckland City Hospital, Auckland, New Zealand; ${ }^{4}$ Department of Radiology, Hospital Vithas Nueve de Octubre, Valencia, Spain \\ Correspondence to: Paolo Simoni, MD, PhD, MBA. Diagnostic Imaging Department, Queen Fabiola Children's University Hospital, Université Libre \\ de Bruxelle, Avenue Jean Joseph Crocq, 15, 1020 Bruxelles, Belgium. Email: paoloemiliosimoni@gmail.com.
}

\begin{abstract}
Overweight and obesity in children and adolescents have become a worldwide public health concern with an ever-increasing prevalence. An excessive accumulation of intraabdominal fat tissue increases the risk of developing insulin resistance, diabetes, and cardiovascular diseases in adulthood. Body composition has a role in metabolism regulation in children and adolescents with differences between genders and age groups. Until recently, Air Displacement Plethysmography and Dual-energy X-ray Absorptiometry (DXA) have been the most common techniques used to assess body composition in children. Ultrasound (US) is an accurate, readily available, and radiation-free technique to quantify intra-abdominal fat in adults, but its use in children has not yet been validated. Computed tomography (CT) is a reliable tool to assess body composition, but its use in children should be avoided due to the significant radiation burden. Quantitative Magnetic Resonance Imaging (qMRI) provides an accurate measurement of body composition, through the quantification of the visceral adipose tissue (VAT), subcutaneous adipose tissue (SAT), and brown adipose tissue (BAT), as well as lean mass. Furthermore, qMRI provides other significant estimates such as the Proton Density Fat-Fraction of the fat tissue. This review article aims to briefly describe the state of art of the advanced imaging techniques to provide a quantitative assessment of body composition in children and adolescents.
\end{abstract}

Keywords: Body composition; children; magnetic resonance imaging; ultrasound (US); computed tomography (CT); Dual-energy X-ray Absorptiometry (DXA)

Submitted Dec 08, 2019. Accepted for publication Mar 17, 2020.

doi: 10.21037/qims.2020.04.06

View this article at: http://dx.doi.org/10.21037/qims.2020.04.06

\section{Introduction}

Childhood overweight and obesity have become a worldwide public health concern with an ever-increasing prevalence (1) leading to the development of cardiovascular disease (2-4). Indeed, visceral adipose tissue (VAT) has been proven to have an important metabolic activity, secreting inflammatory markers into the portal circulation, with an increased effect on cardiometabolic risk (5). The intrabdominal fat, commonly referred to as VAT, induces a chronic inflammatory response by specific mediators secreted by VAT adipocytes. This cascade leads to insulin resistance and the development of diabetes.
The literature about body composition in children and adolescents is still limited (6). The limited number of studies of body composition conducted in children provide evidence that is not in keeping with what is observed in adults. As an example, VAT influences glucose metabolism in children only after puberty (7). In adolescents, VAT is related to insulin sensitivity and high-density lipoprotein cholesterol levels (8). Besides, in overweight and obese prepubertal children, unlike in adults, insulin sensitivity is associated with subcutaneous adipose tissue (SAT) but not with VAT (9).

The presence of lipids in other locations, like the liver 
and skeletal muscle, has also been associated with adverse metabolic phenotypes and insulin resistance, independently of total body adiposity. Differently to what happens with VAT, the role of the SAT compartment is controversial in adults, from a negative role in the development of insulin resistance (especially at abdominal level) to a protective role (10).

The complex interaction of fat and lean mass with the metabolic syndrome has triggered a vivid interest in the quantification of specific adipose tissue compartments in the body. Several techniques are available to assess body composition at different escalating levels, from atomic to molecular and then cellular, to evolve into organ-tissue and finally whole-body assessment $(11,12)$. The technical advances applied to specific imaging techniques have allowed the development of reproducible and reliable tools, which overperform the standard anthropometric measurements for the assessment of body composition and have a predictive value on the risk of development of specific diseases in children (6).

Until recently, Air Displacement Plethysmography (ADP) and Dual-energy X-ray Absorptiometry (DXA) have been the most commonly used techniques to estimate fat mass $(F M)$ in children $(13,14)$. The estimation of the FM by ADP and DXA is performed indirectly, using post-processing algorithms and body modeling $(13,14)$. Currently, there are no ADP devices available for children under 6 years (13). Also, ADP requires DXA to estimate the bone mineral content (BMC) and deuterium oxide dilution for total body water to calculate the FM more accurately by a four-component (4C) (15) or five component model (11). DXA has been used as a reliable tool to assess FM in children in different studies, with substantial technical improvement over time (16-18). Nevertheless, DXA still involves exposure to ionizing radiation and this represents a concern when examinations have to be repeated over time, even if the effective dose of a single examination is as low as 1 micro-Sievert (19). Computed tomography (CT) is considered as the gold standard to measure intra-abdominal fat (20). CT can also accurately estimate VAT. CT can provide an accurate assessment of fat content in the liver (21) and muscles (22). Notably, hepatic fat measured by CT was explicitly related to insulin resistance (6). However, the use of CT in children is considered inappropriate due to the significant radiation burden (22).

Magnetic resonance imaging (MRI) is the emerging technique to assess body composition in children and adolescents (23). It has been proven that MRI has an accuracy comparable to that of CT to quantify SAT and VAT in obese adults (24) and adolescents (20). MRI does not require radiation, which is the main limitation for the use of CT in children and adolescents. MRI is particularly suitable to quantify abdominal fat in children because it requires only a few minutes without compromise in imaging quality (23). MRI also allows an estimation of the fat fraction of brown adipose tissue (BAT), expressed as a percentage, which is inversely associated with VAT (25). Advanced imaging techniques such as MRI and Positron emission tomography computed tomography (PETCT) have paved the way for a "functional" study of body composition (26). These models may also guide therapeutic and prophylactic interventions to avoid malnutrition and metabolic disease in children suffering from chronic disease (27).

This review aims to briefly describe the role of the advanced imaging to provide a quantitative assessment of the different fat components including the lean tissue in children and adolescents.

\section{DXA to assess body composition in children}

DXA was traditionally considered as the reference standard for the measurement of the BMC (28). DXA uses two $\mathrm{X}$-ray beams of different energy. The ratio between the degree of attenuation of the lower energy and the higher energy beam is specific for each tissue ("R-value"). From the R-value, using sophisticated algorithms, it is possible to obtain the amount of BMC from the pixels that contain bone. The ratio $\mathrm{BMC} / \mathrm{area}$ (in $\mathrm{g} / \mathrm{cm}^{2}$ ) represents the bone mineral density (BMD) (29). The total body calcium can be calculated using the known attenuation of hydroxyapatite [calcium $(\mathrm{g})=0.34 \times \mathrm{BMC}(\mathrm{g})]$ (28) (Figure 1).

Beyond the measurement of total body calcium, DXA has also been used to analyze other components of body composition in adults and children (28). The dual-energy $\mathrm{X}$-ray emission enables DXA to measure mineral density but also to estimate the total and regional fat mass and the lean tissue (values expressed in $\mathrm{cm}^{2}$ ) (28) (Figure 1). Just as seen with bone, mathematical algorithms allow to distinguish different tissues (fat, bone, muscles) based on the attenuation differences between the two levels of energy by a pixel-by-pixel analysis using tissue-standardized thresholds (28). Interpolation techniques then allow to confidently estimate the relative percentage of each tissue in areas in which calcium, lean mass, and fat are present in small volumes (30). Subsequently, regional volumes of 

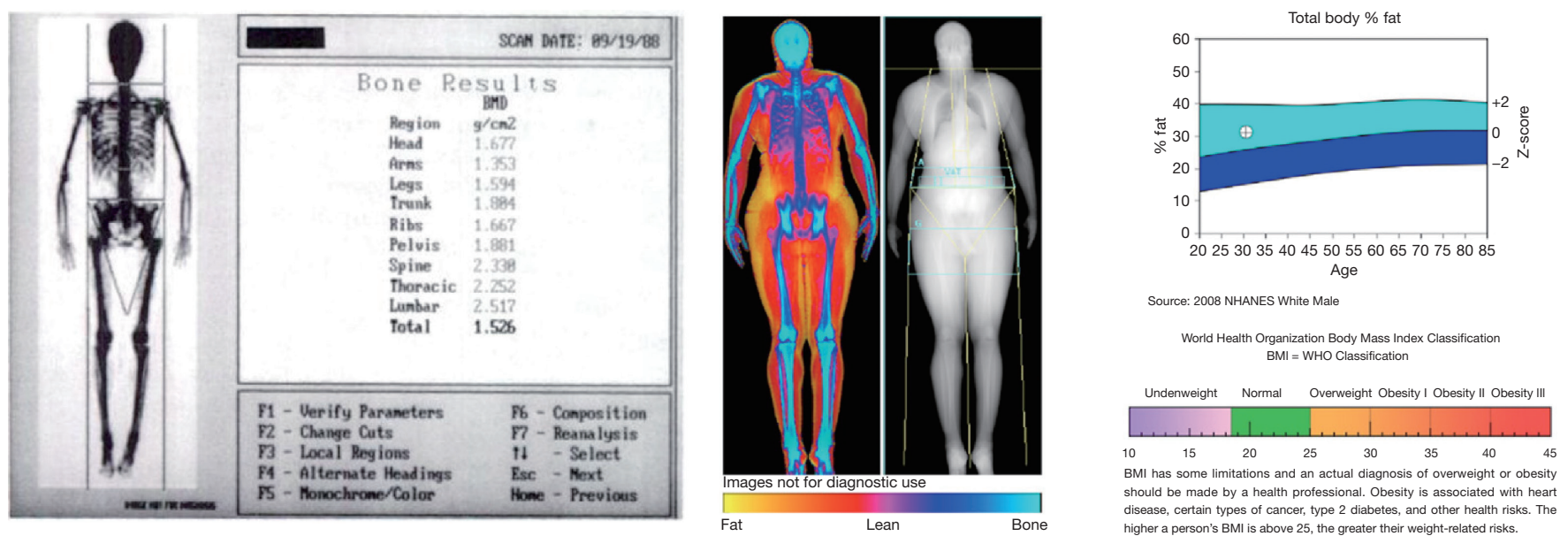

Figure 1 Left (in black and white): screen Capture from a Lunar DPX pencil beam system (1988) for the measurement of bone mass. Right (color) from Hologic Horizon (2016) DXA for the study of body composition [reproduced with permission from Shepherd JA: Body composition by DXA Bone (2017) 104 101-105].

fat and lean tissue are estimated by analyzing data using models that confidently outline body shapes, to create an anatomical model. These models allow the detection of phenotypes at risk based on bi-dimensional images (28). From the anatomical model, VAT and SAT can be estimated. A reliable measurement of the SAT thickness can be obtained, and subtracting this volume to the total fat it is possible to estimate VAT (28).

A recently introduced DXA tool allows the analysis of VAT and SAT in the android region [a segment of the abdomen comprised between a lower demarcation line joining the superior limits of the iliac crests and an upper demarcation line drawn at $20 \%$ of the distance in between the iliac crests line and the mentum (chin)]. SAT can be estimated and then subtracted from total android FM to obtain VAT (in grams and volume) (31). DXA-assessed VAT measurement has been validated against CT in adults for a wide range of age (18-90 years old) and BMI $\left(18-40 \mathrm{~kg} / \mathrm{m}^{2}\right)(31)$. DXA has been proven to be a reliable tool to assess FM in children (16-18). However, there is still concern that this involves the use of ionizing radiation, even if the effective dose of a single examination is as low as 1 micro-Sievert (19).

The main limitation of DXA analysis relies on its bidimensional assessment and the assumption of constant hydration of the lean soft tissues. In the clinical setting, the content of water varies depending on age, gender, and between healthy and ill individuals. Notwithstanding this inherent bias, DXA has excellent repeatability, with variations as low as $1-2 \%$ for body fat and $0.5-2 \%$ for lean tissue (19). Another limitation of DXA is the impossibility to determine the fat fraction in solid organs such as liver or muscle (28).

The literature about the use of DXA to assess body composition in children is limited compared to that available for adults (32). Staiano and coworkers (32) studied a cohort of children and adolescents of both genders of different ethnicity, from 5 to 18 years of age. In their study, the authors found total fat mass was higher in girls but VAT values were higher in boys. The covariate analysis showed that Caucasian children had a higher VAT than Afro-American children, and males had a higher amount of VAT than females at all ages. The influence of ethnicity and gender was different between age groups.

A study conducted with DXA by Verduin et al. (4) focusing on Dutch children between 10 and 11 years of age with healthy BMI confirmed that in non-obese children, boys tended to have more VAT and lean mass but less total fat mass compared with girls. Unlike other DXA studies on healthy children, Druet et al. (33) found no statistical difference between girls and boys in total fat mass and VAT obtained by DXA examination in 159 overweight or obese children and adolescents. These data suggest that the gender difference in total fat mass in children with an average healthy weight may not be present in obese or overweight children and adolescents.

DXA was also employed by Haas and coworkers (34) to assess the nutritional status of adolescents with anorexia 

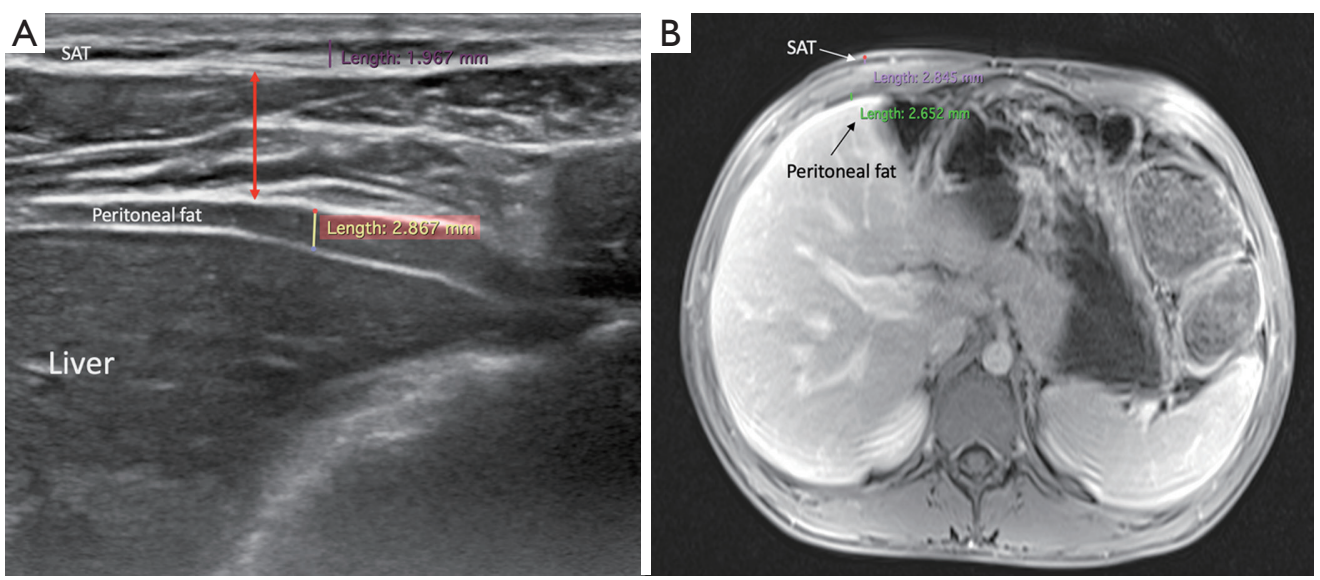

Figure 2 Ultrasound (A) and abdominal-MRI (B) of a 15-year-old boy. After treatment follow-up of Crohn's disease. (A) Standard measurements performed with high-frequence (12 MhZ linear probe): Peritoneal fat thickness (yellow line), measured on the transverse plane, anterior to the liver, compared to the SAT thickness (purple line) at the same level (sub-xyphoid region, mid-clavicular line). The thickness of the abdominal wall muscles has also been obtained (red arrow); (B) MRI image at the same level of the ultrasound image (T1weighted image after contrast injection) in the same patient. Peritoneal fat thickness (green line), SAT thickness (indicated by the white arrow and measured as the purple line). The correlation between ultrasound and MRI is quite accurate. SAT, subcutaneous adipose tissue.

nervosa. DXA can be used to measure total lean mass in female adolescents with anorexia nervosa. The results of DXA were compared to total body protein depletion estimation by in vivo neutron activation analysis. This study showed a limited capability of DXA to detect a decrease in the total lean mass, suggesting other techniques may be more useful for this purpose.

\section{Ultrasound (US)}

US is a noninvasive, accurate, reproducible, fast, available, and costless alternative to estimate adiposity in clinical practice. Given that it does not involve radiation, US may be an ideal method for the evaluation of young people and for follow-up studies, in which multiple measurements need to be taken (fat changes in response to treatments, for example) (35).

Direct measurements of VAT and SAT thicknesses at different axial sections of the abdomen can be obtained (Figures 2,3). In children and adolescents, it was demonstrated that epicardial fat thickness was correlated to obesity, subclinical carotid atherosclerosis and cardiac geometry parameters, with the possibility to be used as a tool for stratification of cardiovascular risk in this population (36) (Figure 4).

The measurement of subcutaneous fat thickness has been demonstrated to have a good correlation with MR- and
CT- derived subcutaneous tissue areas, and the minimal and maximal subcutaneous fat thickness good correlation with CT- derived subcutaneous tissue area. Other parameters, such as abdominal wall fat index, pre-peritoneal fat thickness, and mesenteric fat thickness, have been seen to yield variable reliability and accuracy in adult studies (37).

For the study of lean tissue, US can be used to determine thickness, cross-sectional area, echogenicity, fascicle length, and the pennation angle of muscles. In pennate muscles, the pennation angle (angle formed at the attachment site of the fibers into deep and superficial aponeurosis) can be evaluated in static and dynamic conditions, thus providing information about mechanical and contractile properties beyond the mere determination of the mass (38).

Ultrasound-derived measurements of muscle mass have shown a good-to-high level of correlation with those derived from reference methods (CT and MRI) (39). The analysis of lean mass is particularly relevant in the cases of children in critical care units, as well as in the study of neuromuscular disease, to assess lean mass wasting, which affects prognosis. The decrease in quadriceps femoris thickness was proposed as a surrogate for the assessment of the frequent, quick, and intense loss of muscle mass that happens in pediatric intensive care units (40). Muscle echogenicity, which gives an insight on intracellular fat content in muscle, could be another property to evaluate in critically ill children (41). 

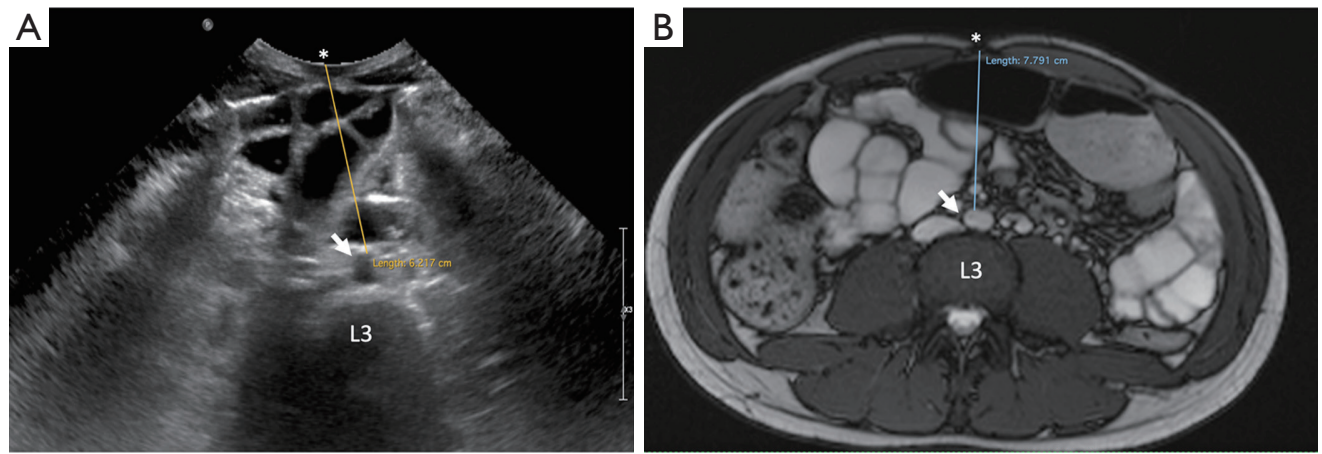

Figure 3 Ultrasound (A) and abdominal-MRI (B) of a 15-year-old boy. After treatment follow-up of Crohn's disease (same patient as in Figure 2). (A) The VAT thickness is measured on the transverse plane at the level of the umbilicus (linea alba) $\left(^{*}\right)$ as the distance from the umbilicus to the anterior wall of the aorta (white arrow) at the level of the L3 vertebral body. (B) Correlation with the MRI image at the same level of the ultrasound image with the MRI measurement on true fast imaging with steady state free precession (True-FISP) image. Note the variation in magnitude of the fat measurement in the same patient using the two different techniques (even though this was performed during the same diagnostic session). Ultrasound is an operator-dependent technique, and as such, technique has to be precise and standardized (supine position, expiration, arms along the body), otherwise error may be introduced. VAT, visceral adipose tissue.

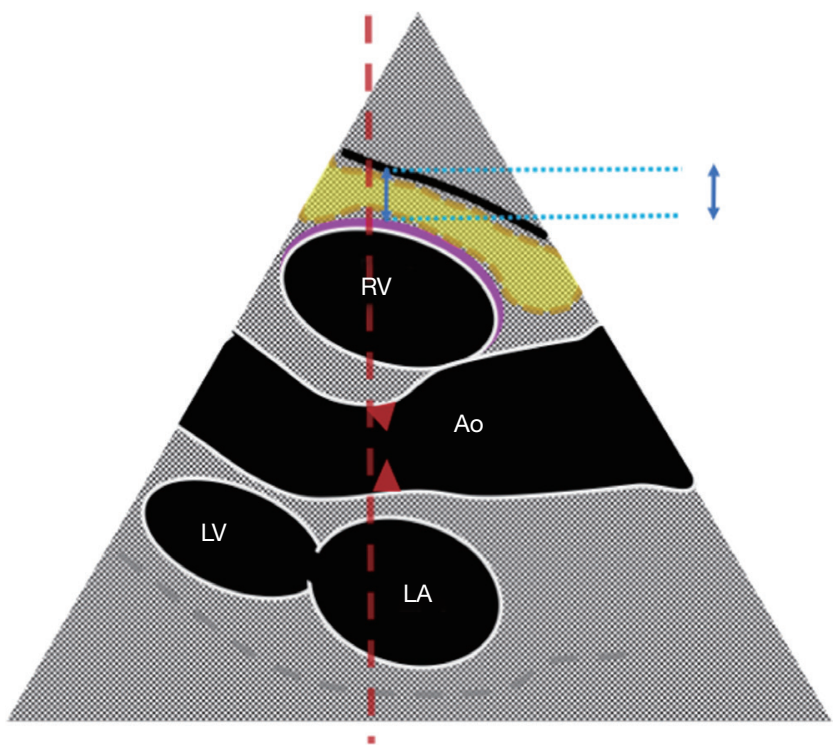

Figure 4 Epicardial thickness on US: scheme of the standard measurement on the left parasternal long-axis view. The thickness of the epicardial fat is depicted as the blue double arrow. The epicardial fat (yellow area) is located in the space between the outer wall of the myocardium at the right ventricle (pink line) and the visceral layer of the pericardium (black line). This measurement is obtained with the parasternal long-axis view, at the end of the systole. The landmark for the measurement is the plane of the ultrasound beam (red discontinuous line), which has to be as perpendicular as possible to the aortic annulus (red arrows). RV, right ventricle; LV, left ventricle; LA, left atrium; Ao, aorta.
Ultrasound for the assessment of lean mass is promising, but to date, none of the operative definitions of sarcopenia in adults or children and adolescents include ultrasound in its diagnostic algorithm (39). Nevertheless, ultrasound is a field of potential investigation for body composition in children and also in newborn due to its vast availability, low cost, and lack of radiation.

\section{CT}

CT offers a three-dimensional image with high resolution of every structure in a selected area. Based on differences in attenuation, fat and lean tissues can be easily separated on tomographic images. Unlike DXA, CT is able to estimate the fat content in skeletal muscle tissue (22) and liver (21). Besides, thanks to its three-dimensional images, CT potentially allows a volumetric measurement of the different tissues. In the clinical setting, in order to reduce the radiation burden, body composition analysis by CT is limited to a selection of axial images, used as a proxy to estimate the total volume of fat and lean mass (42). Besides, the manual segmentation of the different tissue components from the images is a time-consuming task with an inherent inaccuracy due to the choice of the sample at given landmarks. However, CT (along with MRI) is nowadays considered as the gold standard for body composition analysis in children (16).

The use of CT for the assessment of body composition 
in children is restricted to a relatively small number of studies because to reduce radiation exposure, and based on sample slices (22). Asayama et al. (43) studied a population of 290 obese Japanese children aged from 6 to 15 years. CT measurement of VAT was correlated with abnormalities in laboratory tests, including serum triglycerides, alanine aminotransferase and fasting insulin levels. Abnormalities in blood test samples were found in children with a VAT area of more than $54.8 \mathrm{~cm}^{2}$. Satake et al. (44) used CT to study the body composition in 130 Japanese children with normal weight. Children were divided in into three groups of age from 6 to 20 years. Their results showed that higher values of VAT in boys compared to girls were only found in the age group between 16 and 20 years. Klopfenstein et al. (24) found a good agreement between CT and MRI for the measurement of both VAT and SAT. Bland-Altman analysis showed a mean bias of only $-2.9 \%$ (as a portion of the total abdominal area) for VAT and $+0.4 \%$ for SAT, as measured by MRI using CT as a gold standard.

\section{Quantitative MRI (qMRI)}

qMRI uses the properties of the hydrogen contained in water and fat to produce quantitative images of soft tissues (12). Dixon imaging (26) uses the slightly different magnetic resonance frequencies of protons linked to fat and water molecules to distinguish between the signal of fat and water. The set of images provided by the Dixon images includes the images in-phase, the out-of-phase, "fat only", and "water only" is provided by a single acquisition. Dixon imaging (45) has been validated to assess body composition assessment in children. The segmentation and quantitative assessment of adipose tissue by MRI allows an accurate estimation of adipose and lean tissue (Figure 5). The fat infiltration of a specific organ can also be estimated $(13,20,46)$. In particular, through the calculation of the proton density fat fraction (PDFF) (47) it is possible to obtain the quantity of adipose tissue in each voxel (47).

Weiss et al. (48) studied insulin resistance in 28 obese American adolescents. They matched two groups of insulinsensitive and insulin insensitive patients for gender, age, pubertal status and body composition (48). The insulinsensitive group had significantly lower intramyocellular and visceral fat levels, compared with the insulin resistant. The subcutaneous fat area was similar between the two groups. In the same population, waist-hip circumference ratio, which is widely used as an indicator of VAT deposition in adults, was not a useful predictor.
Despite the advantages of qMRI in terms of accuracy and lack of irradiation compared to DXA and CT, its use in the pediatric population is relatively limited (1-4,13,15,20,23,25,32,33,45,49-51). Unlike DXA, MRI provides volumetric three-dimensional imaging, and can be used in healthy volunteers and infants without irradiation. Still, in early studies of body composition a sample set of slices was used as a proxy to estimate VAT and SAT fat volume. More recently, efficient timesaving image analysis tools for three-dimensional segmentation have been developed in adults, which can be applied also in the study of children and adolescents. The use of segmentation software increases the accuracy, reproducibility of the body composition analysis by MRI (19).

In studies in children, qMRI-based fat mass showed a concordance with ADP but gave generally lower systematic values when using deuterium oxide dilution and 4-compartment model as a reference standard $(13,15)$.

The results obtained were significantly associated with total cholesterol/HDL ratio, insulin, and the homeostatic model assessment of insulin resistance (HOMAIR) (20). MRI is a noninvasive research tool to study body composition and hepatic fat also in infants. Body composition and hepatic fat both correlate with the risk of development of metabolic syndrome. Measurements of VAT, SAT, BAT volume and PDFF, and hepatic PDFF can be obtained by using free-breathing radial sequences in very young children, without the need for sedation (45).

De Ridder et al. (52) found that waist, hip, and trochanter circumferences were highly correlated to the total fat surface area both in early and late pubertal girls measured on MRI ( $\mathrm{r}=0.79-0.97)$. In contrast, waist circumference and waist-hip, waist-thigh, or skinfold ratios were not significantly correlated to intra-abdominal fat areas, highlighting the role of MRI in the assessment of intraabdominal fat. When compared to early pubertal girls, the MRI derived amount of subcutaneous fat in late pubertal girls was significantly higher at the trochanter level. They concluded that circumferences at the trunk are good surrogates to measure the quantity of fat in pubertal girls. In contrast, conventional anthropometric measurements, such as trunk-to-extremity skinfold ratio or waist-tohip circumference ratio, could not be used to predict the amount of intra-abdominal fat in pubertal girls. Fox et al. (50) found no significant gender differences in VAT in a sample of 50 11-year-old boys and girls, using MRI.

Quantitative MRI also revealed differences between genders and ethnic groups in terms of fat distribution. In a 


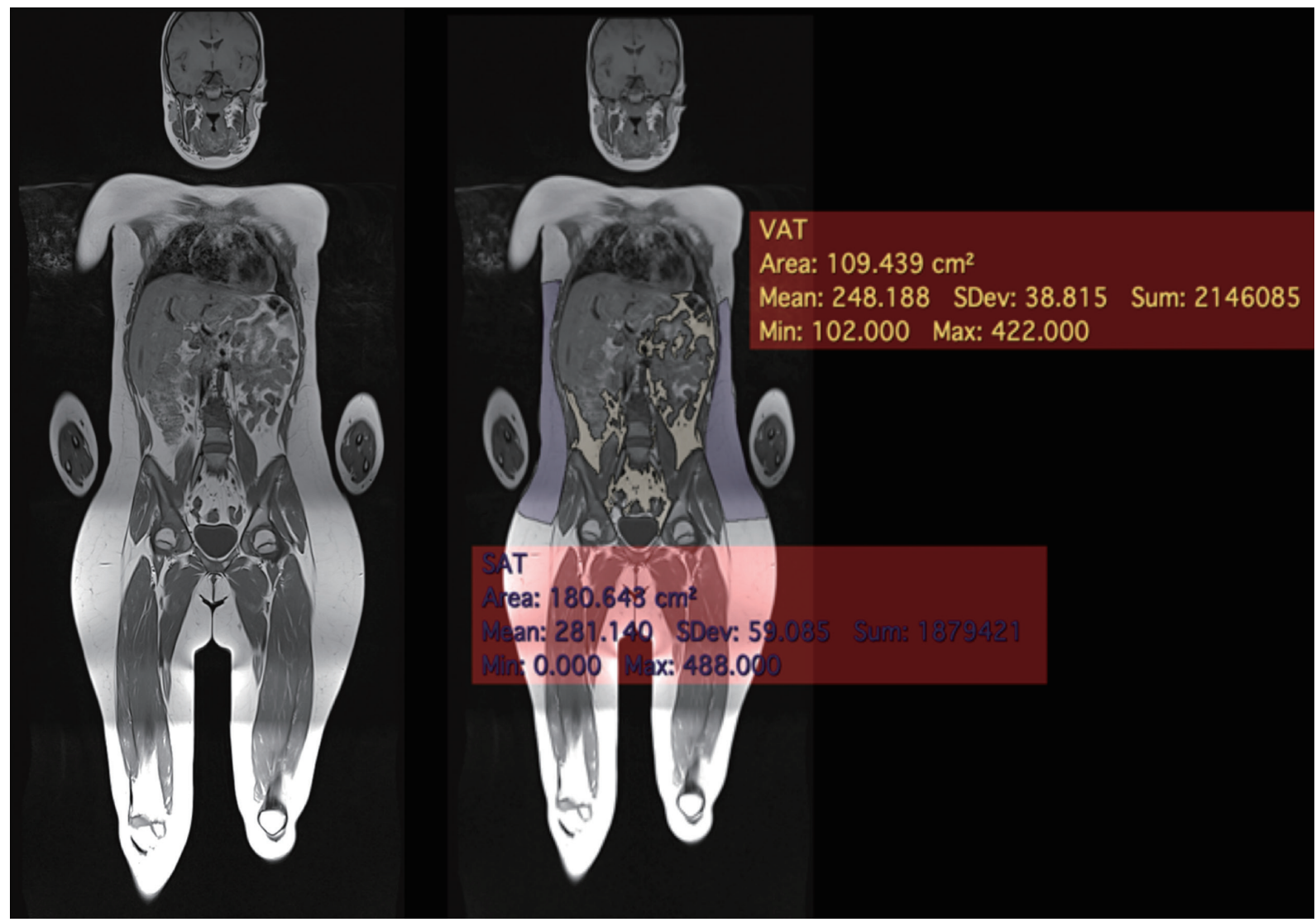

Figure 5 Whole-body MRI in a 12-year-old girl (unremarkable examination performed to rule out bone marrow lesions with the suspicion of a Chronic Recurrent Multifocal Osteomyelitis). Single axial T1-weighted coronal whole-body image was post-processed with the semiautomatic free resource software Horos (https://horosproject.org) using the "brushing tool". VAT can be distinguished from SAT. The values are expressed in $\mathrm{cm}^{2}$. The region of interest for the measurements is the android region, defined as a segment of the abdomen comprised between a lower demarcation line joining the superior limits of the iliac crests and an upper demarcation line drawn at $20 \%$ of the distance in between the iliac crests line and the mentum (chin). VAT, visceral adipose tissue; SAT, subcutaneous adipose tissue.

cross-sectional population of 382 children aged from 5 to 18 years (26), including African-American and Caucasian children, the total body fat, i.e., the total abdominal adipose tissue (total volume and L4-L5 cross-sectional area) including SAT and VAT and the age-adjusted total body fat was higher in African-Americans $(\mathrm{P}=0.017)$ and females $(\mathrm{P}<0.0001)$ compared to Caucasian and males, respectively. The VAT volume was, however, higher in Caucasian $(\mathrm{P}<0.0001)$ and males $(\mathrm{P}<0.0001)$ compared to African-American and females, respectively. Similar differences were observed in SAT and VAT at the level L4-L5.

\section{Brown adipose tissue (BAT)}

More recently, qMRI has been used to quantify the BAT in the cervical, supraclavicular, and axillary fat depots (25). BAT can be distinguished from white adipose tissue by different fat-signal fractions and transverse relaxation time $\left(\mathrm{T}^{*}{ }^{*}\right)$ derived from chemical-shift water-fat MRI. Fat-signal fraare lower in BAT than inctions and T2* estimates, both calculated from chemical-shift waterfat, are lower in BAT than in VAT, likely because of differences in cellular structures, triglyceride content, and vascularization. These differences enable the quantification of BAT (53). The simultaneous use of MRI and PET$\mathrm{CT}$ has also been proposed to define the brown fat location better, but this approach seems not feasible in children (26). Hence, BAT and the fat-fractions of VAT and SAT can be quantified and correlated to other metabolic estimates thanks to the use of qMRI. BAT has been seen 


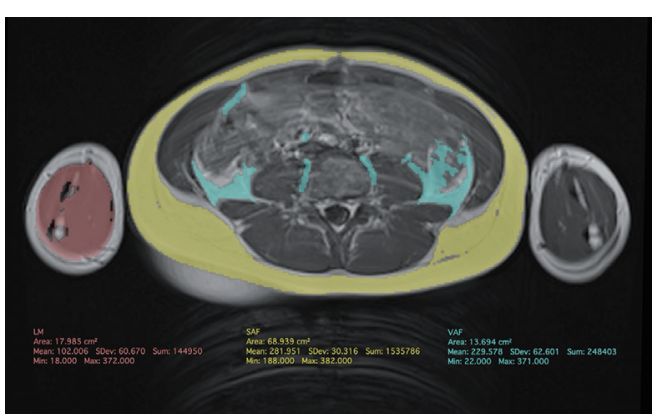

Figure $6 \mathrm{MRI}$ in a 10-year-old boy with unexplained chronic abdominal pain. Clinical examination, laboratory tests and US were normal. Single axial T1-weighted axial image at the level of the 3rd lumbar vertebra was used as proxy to perform quantification. Postprocessing was performed with the semi-automatic free resource software Horos (https://horosproject.org) using the "brushing tool". VAT (in green) can be distinguished from SAT (in yellow). The values are expressed in $\mathrm{cm}^{2}$ along with the LM (in red) of the arm as a proxy of the total lean mass.VAT, visceral adipose tissue; SAT, subcutaneous adipose tissue; LM, lean mass.

to correlate negatively with osteocalcin levels and VAT, while BAT fat-fraction also correlated negatively with thigh muscle volume suggesting a hormonally active role of BAT (25).

As in adults (19), qMRI is considered as the gold standard to assess the lean mass in the pediatric population and has been used as reference to validate the measurements obtained by DXA in the thigh, as a proxy area for the whole-body estimation (54).

Modern automatic segmentation software may be used in the pediatric population to estimate the lean mass with a potential higher regional accuracy (19). Recently, different vendors have developed efficient timesaving software for three-dimensional segmentation. This can be accessed through free online resources such as ImageJ (https://imagej.nih.gov/ij/download.html) and Horos (https://horosproject.org). They focused on adults, but the software can also be used in children and adolescents, and it is expected in the next future this will make qMRI more available in the clinical setting (Figures 5,6). Other groups have developed in-home software, that can be downloaded for free for their use in clinical studies (55).

\section{Perspectives}

The evaluation of body composition in children is a potential cutting-edge field of development of quantitative imaging in pediatric imaging. Ultrasound and qMRI with volumetric assessment still have to be validated in large populations of patients with different metabolic disorders.

Ultrasound is likely to become the more widely used tool in clinical practice because of its broad availability. Adipose tissue content in different anatomical regions can be estimated by proxy standardized sample area, without irradiation. However, US is operator dependent, and its interobserver and intraobserver reproducibility has yet to be assessed in children and adolescents and validated against qMRI.

The new frontier of body composition in children and adults is qMRI, although the literature is still limited compared to the adult population. MRI body composition analysis is now feasible in very young children without the need for sedation, by using free-breathing radial sequences. More recently, efficient timesaving software for threedimensional segmentation has been developed and can be accessed as a free online resource making qMRI analysis broadly available. This will possibly contribute to the expansion of its clinical use in the pediatric population in the near future. Quantitative MRI is likely to completely replace $\mathrm{CT}$ in the next future because of the radiation dose concern. However, CT may still represent a valuable tool for the analysis of body composition in an opportunistic way, in patients suffering from particular conditions requiring repeated imaging evaluations.

\section{Acknowledgments}

Funding: None.

\section{Footnote}

Provenance and Peer Review: With the arrangement by the Guest Editors and the editorial office, this article has been reviewed by external peers.

Conflicts of Interest: All authors have completed the ICMJE uniform disclosure form (available at http://dx.doi. org/10.21037/qims.2020.04.06). The special issue "Body Composition Imaging" was commissioned by the editorial office without any funding or sponsorship. The authors have no other conflicts of interest to declare.

Open Access Statement: This is an Open Access article distributed in accordance with the Creative Commons 
Attribution-NonCommercial-NoDerivs 4.0 International License (CC BY-NC-ND 4.0), which permits the noncommercial replication and distribution of the article with the strict proviso that no changes or edits are made and the original work is properly cited (including links to both the formal publication through the relevant DOI and the license). See: https://creativecommons.org/licenses/by-nc-nd/4.0/.

\section{References}

1. Llewellyn A, Simmonds M, Owen CG, Woolacott $\mathrm{N}$. Childhood obesity as a predictor of morbidity in adulthood: a systematic review and meta-analysis. Obesity Reviews 2016;17:56-67.

2. Goran MI, Nagy TR, Treuth MS, Trowbridge C, Dezenberg C, McGloin A, Gower BA. Visceral fat in white and African American prepubertal children. Am J Clin Nutr 1997;65:1703-8.

3. Huang TT, Johnson MS, Figueroa-Colon R, Dwyer JH, Goran MI. Growth of visceral fat, subcutaneous abdominal fat, and total body fat in children. Obes Res 2001;9:283-9.

4. Verduin WM, Van Den Helder R, Doodeman HJ, Struijf E, Houdijk AP. Dexa Body Composition Assessment in 10-11 Year Healthy Children. PLoS One 2016;11:e0165275.

5. Fox CS, Massaro JM, Hoffmann U, Pou KM, MaurovichHorvat P, Liu CY, Vasan RS, Murabito JM, Meigs JB, Cupples LA, D'Agostino RB, Sr., O'Donnell CJ. Abdominal visceral and subcutaneous adipose tissue compartments: association with metabolic risk factors in the Framingham Heart Study. Circulation 2007;116:39-48.

6. Kabir M, Catalano KJ, Ananthnarayan S, Kim SP, Van Citters GW, Dea MK, Bergman RN. Molecular evidence supporting the portal theory: a causative link between visceral adiposity and hepatic insulin resistance. Am J Physiol Endocrinol Metab 2005;288:E454-61.

7. Brambilla P, Manzoni P, Agostini G, Beccaria L, Ruotolo G, Sironi S, Del Maschio A, Chiumello G. Persisting obesity starting before puberty is associated with stable intraabdominal fat during adolescence. Int J Obes Relat Metab Disord 1999;23:299-303.

8. Brambilla P, Manzoni P, Sironi S, Simone P, Del Maschio A, di Natale B, Chiumello G. Peripheral and abdominal adiposity in childhood obesity. Int J Obes Relat Metab Disord 1994;18:795-800.

9. Maffeis C, Manfredi R, Trombetta M, Sordelli S, Storti M, Benuzzi T, Bonadonna RC. Insulin sensitivity is correlated with subcutaneous but not visceral body fat in overweight and obese prepubertal children. J Clin Endocrinol Metab
2008;93:2122-8.

10. Patel P, Abate N. Role of subcutaneous adipose tissue in the pathogenesis of insulin resistance. J Obes 2013;2013:489187.

11. Wang ZM, Pierson RN, Jr., Heymsfield SB. The five-level model: a new approach to organizing body-composition research. Am J Clin Nutr 1992;56:19-28.

12. Lee SY, Gallagher D. Assessment methods in human body composition. Curr Opin Clin Nutr Metab Care 2008;11:566-72.

13. Chen LW, Tint MT, Fortier MV, Aris IM, Shek LP, Tan KH, Rajadurai VS, Gluckman PD, Chong YS, Godfrey KM, Kramer MS, Henry CJ, Yap F, Lee YS. Body composition measurement in young children using quantitative magnetic resonance: a comparison with air displacement plethysmography. Pediatr Obes 2018;13:365-73.

14. Gao Y, Zong K, Gao Z, Rubin MR, Chen J, Heymsfield SB, Gallagher D, Shen W. Magnetic resonance imagingmeasured bone marrow adipose tissue area is inversely related to cortical bone area in children and adolescents aged 5-18 years. J Clin Densitom 2015;18:203-8.

15. Fields DA, Goran MI, McCrory MA. Body-composition assessment via air-displacement plethysmography in adults and children: a review. Am J Clin Nutr 2002;75:453-67.

16. Andres A, Gomez-Acevedo H, Badger TM. Quantitative nuclear magnetic resonance to measure fat mass in infants and children. Obesity (Silver Spring) 2011;19:2089-95.

17. Chomtho S, Wells JC, Williams JE, Davies PS, Lucas A, Fewtrell MS. Infant growth and later body composition: evidence from the 4-component model. Am J Clin Nutr 2008;87:1776-84.

18. Deurenberg P. Limitations of the bioelectrical impedance method for the assessment of body fat in severe obesity. Am J Clin Nutr 1996;64:449S-52S.

19. Borga M, West J, Bell JD, Harvey NC, Romu T, Heymsfield SB, Dahlqvist Leinhard O. Advanced body composition assessment: from body mass index to body composition profiling. J Investig Med 2018;66:1-9.

20. Eloi JC, Epifanio M, de Goncalves MM, Pellicioli A, Vieira PF, Dias HB, Bruscato N, Soder RB, Santana JC, Mouzaki M, Baldisserotto M. Quantification of Abdominal Fat in Obese and Healthy Adolescents Using 3 Tesla Magnetic Resonance Imaging and Free Software for Image Analysis. PLoS One 2017;12:e0167625.

21. Kramer H, Pickhardt PJ, Kliewer MA, Hernando D, Chen GH, Zagzebski JA, Reeder SB. Accuracy of Liver Fat Quantification With Advanced CT, MRI, and Ultrasound 
Techniques: Prospective Comparison With MR

Spectroscopy. AJR Am J Roentgenol 2017;208:92-100.

22. Goodpaster BH, Kelley DE, Thaete FL, He J, Ross R. Skeletal muscle attenuation determined by computed tomography is associated with skeletal muscle lipid content. J Appl Physiol (1985) 2000;89:104-10.

23. Ly KV, Armstrong T, Yeh J, Ghahremani S, Kim GH, Wu $\mathrm{HH}$, Calkins KL. Free-breathing Magnetic Resonance Imaging Assessment of Body Composition in Healthy and Overweight Children: An Observational Study. J Pediatr Gastroenterol Nutr 2019;68:782-7.

24. Klopfenstein BJ, Kim MS, Krisky CM, Szumowski J, Rooney WD, Purnell JQ. Comparison of 3 T MRI and CT for the measurement of visceral and subcutaneous adipose tissue in humans. Br J Radiol 2012;85:e826-30.

25. Andersson J, Roswall J, Kjellberg E, Ahlstrom H, Dahlgren J, Kullberg J. MRI estimates of brown adipose tissue in children - Associations to adiposity, osteocalcin, and thigh muscle volume. Magn Reson Imaging 2019;58:135-42.

26. Franz D, Karampinos DC, Rummeny EJ, Souvatzoglou M, Beer AJ, Nekolla SG, Schwaiger M, Eiber M. Discrimination Between Brown and White Adipose Tissue Using a 2-Point Dixon Water-Fat Separation Method in Simultaneous PET/MRI. J Nucl Med 2015;56:1742-7.

27. Weber DR, Leonard MB, Zemel BS. Body composition analysis in the pediatric population. Pediatr Endocrinol Rev 2012;10:130-9.

28. Shepherd JA, Ng BK, Sommer MJ, Heymsfield SB. Body composition by DXA. Bone 2017;104:101-5.

29. Guglielmi G, Muscarella S, Bazzocchi A. Integrated imaging approach to osteoporosis: state-of-the-art review and update. Radiographics 2011;31:1343-64.

30. Luca T, Claudio M, Marita B, Roberta G. Measure of body composition by MOC DEXA, in children and teenagers with eating disorders. Progress in Nutrition 2018. doi: 10.23751/pn.v19i4.6672.

31. Kaul S, Rothney MP, Peters DM, Wacker WK, Davis CE, Shapiro MD, Ergun DL. Dual-energy X-ray absorptiometry for quantification of visceral fat. Obesity (Silver Spring) 2012;20:1313-8.

32. Staiano AE, Broyles ST, Gupta AK, Katzmarzyk PT. Ethnic and sex differences in visceral, subcutaneous, and total body fat in children and adolescents. Obesity (Silver Spring) 2013;21:1251-5.

33. Druet C, Baltakse V, Chevenne D, Dorgeret S, Zaccaria I, Wang Y, Levy-Marchal C. Independent effect of visceral adipose tissue on metabolic syndrome in obese adolescents. Horm Res 2008;70:22-8.
34. Haas VK, Kohn MR, Clarke SD, Allen JR, Madden S, Muller MJ, Gaskin KJ. Body composition changes in female adolescents with anorexia nervosa. Am J Clin Nutr 2009;89:1005-10.

35. Bazzocchi A, Filonzi G, Ponti F, Amadori M, Sassi C, Salizzoni E, Albisinni U, Battista G. The role of ultrasonography in the evaluation of abdominal fat: analysis of technical and methodological issues. Acad Radiol 2013;20:1278-85.

36. Cabrera-Rego JO, Iacobellis G, Castillo-Herrera JA, Valiente-Mustelier J, Gandarilla-Sarmientos JC, MarinJulia SM, Navarrete-Cabrera J. Epicardial fat thickness correlates with carotid intima-media thickness, arterial stiffness, and cardiac geometry in children and adolescents. Pediatr Cardiol 2014;35:450-6.

37. Bazzocchi A, Filonzi G, Ponti F, Albisinni U, Guglielmi G, Battista G. Ultrasound: Which role in body composition? Eur J Radiol 2016;85:1469-80.

38. Narici M, Franchi M, Maganaris C. Muscle structural assembly and functional consequences. J Exp Biol 2016;219:276-84.

39. Ticinesi A, Meschi T, Narici MV, Lauretani F, Maggio M. Muscle Ultrasound and Sarcopenia in Older Individuals: A Clinical Perspective. J Am Med Dir Assoc 2017;18:290-300.

40. Valla FV, Young DK, Rabilloud M, Periasami U, John M, Baudin F, Vuillerot C, Portefaix A, White D, Ridout JA, Meyer R, Gaillard Le Roux B, Javouhey E, Pathan N. Thigh Ultrasound Monitoring Identifies Decreases in Quadriceps Femoris Thickness as a Frequent Observation in Critically Ill Children. Pediatr Crit Care Med 2017;18:e339-47.

41. Ong C, Lee JH, Leow MKS, Puthucheary ZA. Skeletal Muscle Ultrasonography in Nutrition and Functional Outcome Assessment of Critically Ill Children: Experience and Insights From Pediatric Disease and Adult Critical Care Studies [Formula: see text]. JPEN J Parenter Enteral Nutr 2017;41:1091-9.

42. Yu L, Christner JA, Leng S, Wang J, Fletcher JG, McCollough CH. Virtual monochromatic imaging in dualsource dual-energy CT: Radiation dose and image quality. Medical Physics 2011;38:6371-9.

43. Asayama K, Hayashibe H, Endo A, Okada T, Hara M, Masuda H, Sugihara S. Threshold values of visceral fat and waist girth in Japanese obese children. Pediatr Int 2005;47:498-504.

44. Satake E, Nakagawa Y, Kubota A, Saegusa H, Sano S, Ohzeki T. Age and sex differences in fat distribution in 
non-obese Japanese children. J Pediatr Endocrinol Metab 2010;23:873-8.

45. Shearrer GE, House BT, Gallas MC, Luci JJ, Davis JN. Fat Imaging via Magnetic Resonance Imaging (MRI) in Young Children (Ages 1-4 Years) without sedation. PLoS One 2016;11:e0149744.

46. Armstrong T, Ly KV, Ghahremani S, Calkins KL, Wu HH. Free-breathing 3-D quantification of infant body composition and hepatic fat using a stack-of-radial magnetic resonance imaging technique. Pediatr Radiol 2019;49:876-88.

47. Reeder SB, Hu HH, Sirlin CB. Proton density fatfraction: A standardized mr-based biomarker of tissue fat concentration. J Magn Reson Imaging 2012;36:1011-4.

48. Weiss R, Taksali SE, Dufour S, Yeckel CW, Papademetris X, Cline G, Tamborlane WV, Dziura J, Shulman GI, Caprio S. The "Obese Insulin-Sensitive" Adolescent: Importance of Adiponectin and Lipid Partitioning. J Clin Endocrinol Metab 2005;90:3731-7.

49. Deng J, Schoeneman SE, Zhang H, Kwon S, Rigsby CK, Shore RM, Josefson JL. MRI characterization of brown adipose tissue in obese and normal-weight children. Pediatr Radiol 2015;45:1682-9.

50. Fox K, Peters D, Armstrong N, Sharpe P, Bell M.

Cite this article as: Simoni P, Guglielmi R, Aparisi Gómez MP. Imaging of body composition in children. Quant Imaging Med Surg 2020;10(8):1661-1671. doi: 10.21037/qims.2020.04.06
Abdominal fat deposition in 11-year-old children. Int J Obes Relat Metab Disord 1993;17:11-6.

51. Goran MI, Gower BA, Treuth M, Nagy TR. Prediction of intra-abdominal and subcutaneous abdominal adipose tissue in healthy prepubertal children. Int J Obes Relat Metab Disord 1998;22:549-58.

52. de Ridder CM, de Boer RW, Seidell JC, Nieuwenhoff CM, Jeneson JA, Bakker CJ, Zonderland ML, Erich WB. Body fat distribution in pubertal girls quantified by magnetic resonance imaging. Int J Obes Relat Metab Disord 1992;16:443-9.

53. Hu HH, Perkins TG, Chia JM, Gilsanz V.

Characterization of human brown adipose tissue by chemical-shift water-fat MRI. AJR Am J Roentgenol 2013;200:177-83.

54. Bridge P, Pocock NA, Nguyen T, Munns C, Cowell CT, Forwood N, Thompson MW. Validation of longitudinal DXA changes in body composition from pre- to midadolescence using MRI as reference. J Clin Densitom 2011;14:340-7.

55. Yip C, Dinkel C, Mahajan A, Siddique M, Cook GJ, Goh V. Imaging body composition in cancer patients: visceral obesity, sarcopenia and sarcopenic obesity may impact on clinical outcome. Insights Imaging 2015;6:489-97. 